\title{
Convolvulaceae do Amazonas
}

\author{
JOAQUIM INÁCIO DE ALMEIDA FALCÃo(*)
}

O presente trabalho foi por nós idealizado com o intuito de facilitar a identificação das Convolvulaceae que ocorrem no Estado do Amazonas.

Contamos para sua realização com o amparo do CNPq. e também com a valiosa colaboração do INPA, que nos enviou duplicatas de seu herbário e possibilitou a publicação dêste.

Consta nosso trabalho da descrição sumária de cada gênero e de "chaves" que possibilitam a identificação das respectivas espécies.

\section{CARACTERÍSTICAS DA FAMÍLIA}

Flôres hermafroditas, actinomorfas, geralmente providas de 2 bracteolas; cálice pentâmero, geralmente com sépalas livres entre si ou só concrescidas na. base, de prefloração imbricada; corola gamopétala, alternissépala, infundibuliforme, tubulosa, campanulada ou quase rotácea, com bordo 5-lobado ou profundamente 5-partido; estames 5 (ou 4), geralmente inseridos na base da corola, inclusos ou exsertos; filêtes filiformes; anteras de ovais a lineares, clorsifixas, rimosas; pólen esférico ou ovo.l, geralmente provido de pontas ou acúleos; ovário súpero, constituído de 2 (raramente 3-5) carpelos, 1-2 (ou mais) locular, estilête 1-2 filiforme ou curto; estigma esférico, alongado, linear, filiforme, claviforme.

Ervas anuais ou bianuais, semiarbustos ou arbustos, raramente árvores ou plantas parasitas como Cuscuta, muito freqüentemente com caules ou ramos destrorsos, raramente arbustos áfilos com espinhos, glabras ou pilosas; fôlhas geralmente simples de lineares até largamente cordiformes, freqüente- mente digitadas ou lobadas até partidas, mui. to raramente com estípulas, glabras ou pilosas.

Flôres geralmente vistosas, albas ou co. loridas, raramente pequenas, solitárias ou em inflorescências axilares, dicásios, cachos ou quase umbelas; brácteas pequenas, raramente grandes envolvendo o cálice. Os principais caracteres da família são o estigma e o pólen.

No Brasil, as Convolvulaceae são representadas por 19 gêneros e inúmeras espécies. Dessas, 40 ocorrem no Amazonas a saber :
Aniseia martinicensis (Jacq.) Choisy
Bonamia ferruginea (Choisy) Hallier
Calycobulus glaber (H.B.K.) House
Dicranostyles ampla Ducke
Dicranostyles scandens Benth.
Dicranostyles longifolia Ducke
Evolvulus cardiophyllus Sch.
Evolvulus glomeratus Nees et Mart.
Evolvulus nummularius L.
Evolvulus sericeus Sw.
Ipomoea asarifolia Roem et Sch.
Ipomoea batatas (L.) Lam.
Ipomoea coccinea $\mathrm{L}$.
Ipomoea congesta $\mathrm{R}$. Br.
Ipomoea digitata $\mathrm{L}$.
Ipomoea fastigiata Sweet. var. ciliata Hub.
Ipomoea fistulosa Mart.
Ipomoea purpurea Lam.
Ipomoea sobrevoluta Choisy
Ipomoea sidaefolia Choisy
Jacquemontia hirsuta Choisy
Jacquemontia luxurians (Moric.) Hallier
Jacquemontia tamnifolia (L.) Griseb.
Kuhlmanniella falconiana L. Barroso
Kuhlmanniella holostyla (Dutra) L. Bar- roso

(*) - Pesquisador do Jardim Botânico do Rio de Janeiro e Bolsista do Conselho Nacional de Pesquisas. 


\author{
Kuhlmanniella integra (Ducke) L. Bar- \\ roso \\ Kuhlmanniella laxa (Ducke) L. Barroso \\ Maripa densiflora Benth. \\ Maripa elongata Ducke \\ Maripa paniculata Barb. Rodr. \\ Maripa scandens Aubl. \\ Maripa tenuis Ducke \\ Merremia aturensis (H.B.K.) Hallier. \\ Merremia dissecta (Jacq.) Hallier \\ Merremia macrocalyx (Ruiz et Pav.) \\ O'Donell. \\ Merremia umbellata (L.) Hallier. \\ Operculina alata Urb. \\ Operculina passifloroides (Benth.) Ducke \\ Operculina violacea Barb. Rodr. \\ Lysiostyles scandens Benth.
}

\section{DESCRIÇÃo SUMÁRIA DOS GÊNEROS}

\section{Aniseia Choisy}

Sépalas 5, herbáceas, desiguais. Corola campanulada. Estames inclusos inseridos na corola, quase iguais. Estilêtes indivisos, estígmas 2. Ovário bilocular. Cápsula globosa glabra.

Bonamia $\mathrm{R}$. Br.

Sépalas 5 iguais, imbricadas. Corola campanulada. Ovário bilocular, com 2 óvulos por lóculo. Estilête bífido ou profundamente bipartido. Estigma ca.pitado. Cápsula bilocular.

\section{Calycobolus Choisy}

Sépalas 5. Corola infundibuliforme. Estilête bífido ou dois estilêtes livres; estigma ca. pitado. Cápsula bilocular com 4 sementes.

\section{Dicranostyles Benth.}

Cálice herbáceo com 5 dentes, lobos iguais e imbricados. Corola semi-arredonáada de tubo breve, limbo 5-partido. Estames exsertos em número de 5 , inseridos na corola. Ovário bilocular. Estilête capilar de ápice bífido; estígma capitado.

\section{Evolvulus L.}

Geralmente ervas, com flôres hermafroditas, 5 sépalas, 5 pétalas, 2 estilêtes cada um dos quais bifurcado, estigmas filiformes
Ipomoea $\mathrm{L}$.

Sépalas herbáceas; corola campanulada com áreas epissepálicas, gamopétala; estames inclusos; estigmas ovais; ovário súpero; pólen armado.

\section{Jacquemontia Choisy}

Sépalas 5. Corola infundibuliforme, geralmente azul, violácea ou rôxo claro; estigmas ovais planos.

\section{Kuhlmanniella L. Barroso}

Sépalas 5. Corola 5, campanulada. Estigma de base sagitada.

\section{Maripa Aubl.}

Sépalas 5, imbricadas, coriáceas. Corola campanulada. Estilête 1, estigma 2, um aderente ao outro pela base ou mais acima. Ovário bilocular, com 2 óvulos.

\section{Merremia Dennst.}

Sépalas 5. Corola 5, gamopétala. Anteras torcidas no ápice ou espiraladas. Pólen inerme.

\section{Operculina Manso}

Sépalas grandes, subcoriáceas ou coriáceas. Corola grande, campanulada. Aparêlho reprodutor incluso. Ovário bilocular com 2 óvulos; estilête indiviso, estigma truncado. Fruto pixídio.

\section{Lysiostyles Benth.}

Fôlhas coriáceas de dorso tomentoso-ferrugíneo. Cálice 5-partido, lobos imbricados. Corola sub-rotada, tubo pequeno, 5 partido. Estames 5. Ovário com 1 lóculo. Estigmas 2.

\section{CHAVE PARA GÊNEROS DO AMAZONAS}

1. Dois estilêtes, cada um dos quais bifurcados, estigmas filiformes ........... Evolvulus $L$. Estilêtes não bifurcados ............ 2

2. Um só estigma, inteiro, capitado ..... Dicranostyles Benth. Sem êsse caráter .. 3 
3. Estigma de base sagi-

tada ............. Kuhlmanniella L. Bar. Estigma de base inteira ........... 4

4. Estigmas ovais, planos ............. Jacquemontia Choisy Estigmas ovais globosos ............ Ipomoea $\mathrm{L}$.

5. Anteras torcidas no ápice ou espiraladas Merremia Dennst. Anteras não torcidas 6

6. Estigmas 2, um aderente ao outro pela base ou mais acima Maripa Aubl. Fôlhas coriáceas de dorso tomentoso-ferrugíneo; estigmas capitados .......... Lysiostyles Benth.

7. Fruto pixídio ou de deiscência irregular Operculina Manso Fruto não pixídio .. 8

8. Estilête bífido ou profundamente partido ............. Bonamia $\mathrm{R}$. Br.

Sépalas do verticilo exterior mais largas que as do interior 2 ou mais vêzes .... Aniseia Choisy

CHAVE PARA ESPÉCIES DE MARIPA DO AMAZONAS

1. Base da fôlha cordiforme ou levemente cordiforme (Fig. 1) M. densiflora Base da fôlha não cordiforme ....... 2

2. Eixo da inflorescência com mais de 9 $\mathrm{cm}$. de compr., corola alva ............... paniculata Sem êsses caracteres 3

3. Sépalas exteriores pilosas .............. scandens Seppalas exteriores glabras ....... 4
4. Fôlhas maiores até $13 \mathrm{~cm}$ de comprimen to ............... tenuis

Fôlhas maiores com mais de $13 \mathrm{~cm}$. de comprimento ......M. elongata

Material examinado: RB. 22573, leg. Ducke em 12.11.929; RB. 22500, leg. Spruce, em 1928; RB. 35584, leg. Ducke em 25.11.936; RB. 125220, leg. W. Rodrigues, $5394 \mathrm{em}$ 23.4.963? RB. 125221, leg. W .Rodrigues e Chagas, 12754 em 8.4.962; RB. 125227, leg. W. Rodrigues e Chagas, $4508 \mathrm{em} \mathrm{19.6.962.}$

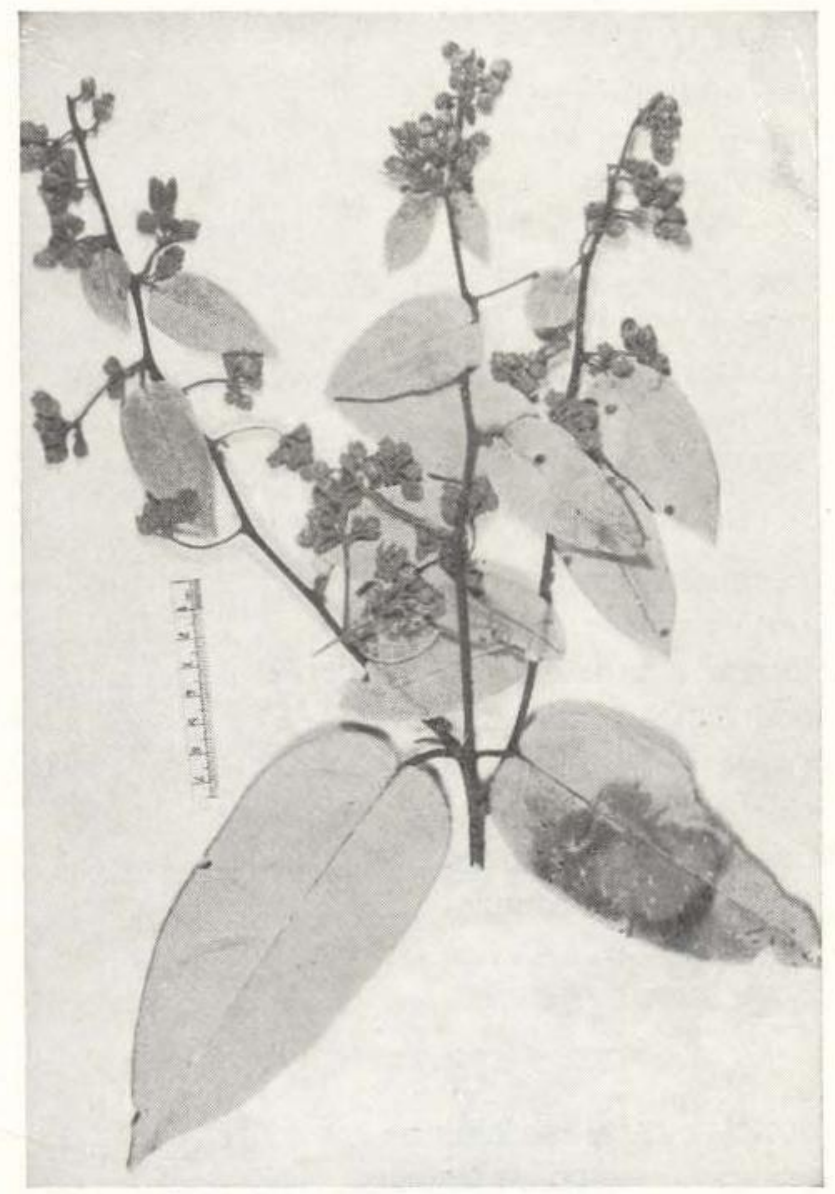

Fig. 1 - Maripa densiflora Benth. 
CHAVE PARA ESPÉCIES DE MERREMIA

DO AMAZONAS

1. Flôres $\in \mathrm{m}$ umbelas multifloras ........M. umbellata Flôres solitárias ou dicásios pauci,floros 2

2. Fôlhas escamiformes ou nulas ......... M. aturensis Fôlhas presentes .. 3

3. Fôlhas palmatisséctas, divididas desde a metade até quase a base em 7-9 segmentos ............. dissecta Sem êsses caracteres 4

4. Segmentos folia res maiores além de $4 \mathrm{~cm}$, de margem inteira, ápice emarginado, mucronado .. $M$. macrocalyx Segmentos foliares maiores até $4 \mathrm{~cm}$, de margem denteada, serreada, ápice agudo acuminado .. $M$. cissoides

Material examinado: RB. 125207, leg. W. Rodrigues, $7 \mathrm{~cm} \mathrm{5.11.954;} \mathrm{RB.} \mathrm{22510,} \mathrm{leg.}$ Kuhlmann em 27.8.923.

\section{CHAVE PARA ESPÉCIES DE DICRANOSTYLES} DO AMAZONAS

1. Pecíolos grossos, flôres pardas densamente agrupadas $\ldots D$. densa S€m êsses caracteres 2

2. Caule e página inferior da fôlha revestidos de um indumento ferrugíneo-amarelado ............ D. longifolia Sem êsses caracteres (Fig. 2) ........ D. scandens

CHAVE PARA ESPÉCIES DE CALYCOBOLUS - do amazonas

Plantas glabras .... C. glaber

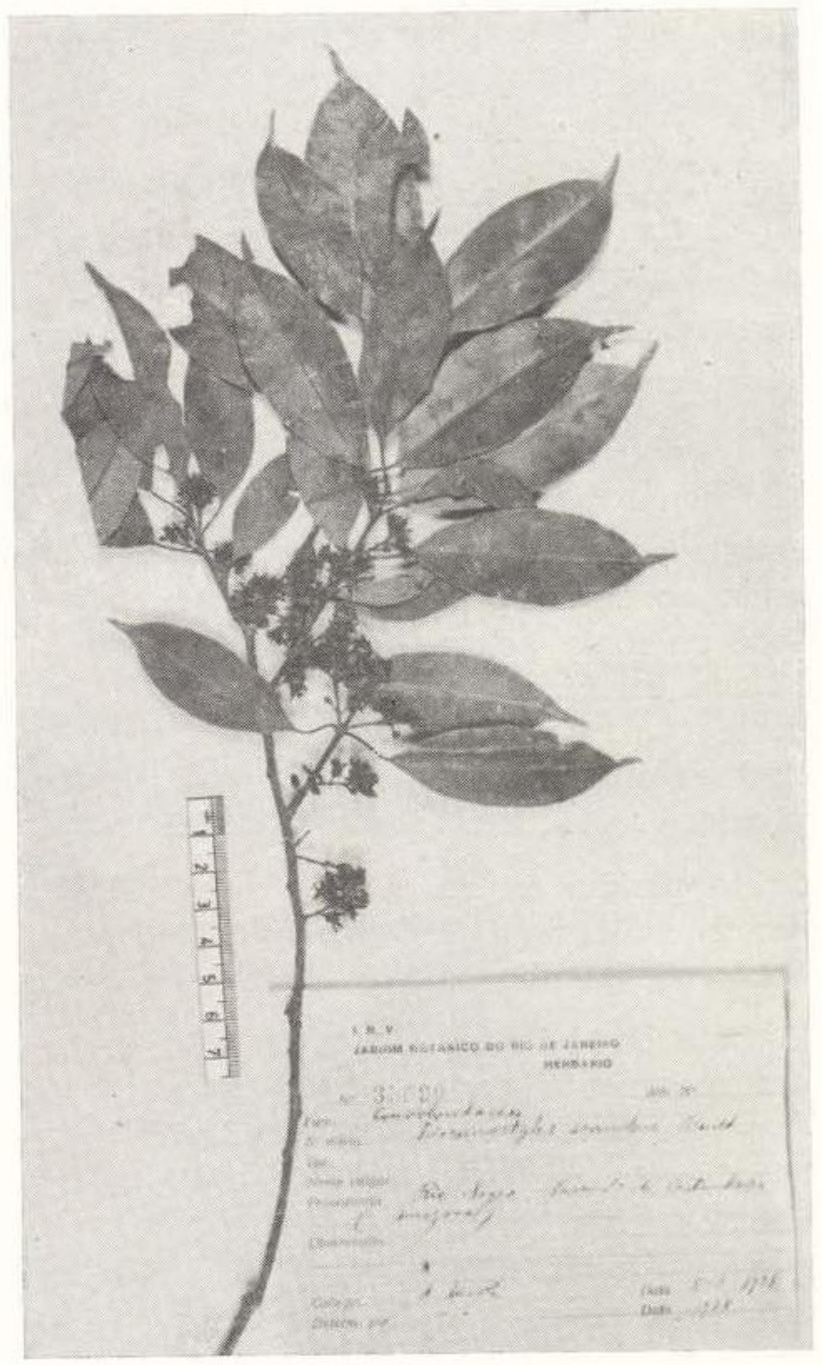

Fig. 2 - Dicranostyles scandens Benth.

CHAVE PARA ESPÉCIES DE KUHLMANNIELLA DO AMAZONAS

1. Ramos e fôlhas glabros ............. holostyla Sem êsses caracteres 2

2. Fôlhas alternas, coriáceas, in te g é $\mathrm{r}$ rimas; inflorescência em rácemo ........ $K$. falconiana Ramos e fôlhas tomentosas ........ K. laxa

Material examinado: RB 22574, leg. Ducke em 7.10.1929. 
CHAVE PARA ESPÉCIES DE IPOMOEA

DO AMAZONAS

1. Fôlhas quinadas ...I. sobrevoluta Fôlhas cordato-ovais, long i - pecioladas, acuminadas; corola lìás ........... I. fastigiata

2. Fôlhas ovais-obiongas, longi-pecioladas, base cordata .......I. fistulosa Sem êsses caracteres 3

3. Fôlhas digitadas ... I. digitata Fôlhas não digitadas 4

4. Fôlhas cordato-reniformes .......... I. asarifolia Fôlhas não reniformes ............ 5

5. Fôlhas cordatas, largamente ovais, indivisas ............ I. purpurea Fôlhas cordatoovais, largamente orbiculares ......... I. sidaefolia.

6. Trepadeiras de flôres amarelo - a verm elhadas ........... I. congesta Sem êsses caracteres 7

7. Cálice corniculado, corola purpúrea ...I. coccinea Fôlhas 3-5 lobadas ou angulosas; corola rósea .............. I. batatas Material examinado: INPA 13703, leg. W. Rodrigues e Chagas, 5042, em 17.4.1963; RB 3471, leg. Kuhlmann em 1931; RB. 125212, leg. W. Rodrigues, Chagas e Lima, $2688 \mathrm{em}$ 2.6.1961.

CHAVE PARA ESPÉCIES DE JACQUEMONTIA DO AMAZONAS

1. Cimeiras umbeliformes ........... J. hirsuta Capítulos hemisféri$\cos$............. J. tamnifolia
2. Trepadeiras, fôlhas o v a l-oblongas, glabras .............J. luxurians

Material examinado: RB. 125216, leg. W. Rodrigues e Chagas, 1537 em 29.3 960; RB. 125217, leg. Coelho e Chagas em 9.3.950.

\section{CHAVE PARA ESPÉCIES DE EVOLVULUS} DO AMAZONAS

1. Fôlhas estritamente lineares .........E. sericeus Fôlhas não lineares 2

2. Fôlhas deltóideovais, g r a ndes, de $3040 \mathrm{~mm}$. por $15-20$ $\mathrm{mm}$. de largura ....E. cardiophyllus Sem êsses caracteres 3

3 . F ôlh a s largamente ovais, flôres 1-2 situadas na axila das fôlhas ........... E. nummularius Fôlhas de forma muito variável, inflorescência globosa ou ovóide (Fig. 3) ...E E. glomeratus

Material examinado: RB. 3166, leg. Kuhlmann em abril de 1913; RB. 125199, leg. W. Rodrigues e Coelho, 4079 em 11.1.1962.

$$
\begin{gathered}
\text { CHAVE PARA ESPÉCIES DE OPERCULINA } \\
\text { DO AMAZONAS }
\end{gathered}
$$

1. Trepadeiras. Fôlhas oblongo-elíticas coriáceas; cimeira $\mathrm{em}$ cacho terminal .... O. passifloroides Sem êsses caracteres 2

2. Árvore. Fôlhas ovais, integérrimas, às vêzes sinuado-anguladas, membranáceas, pedicelo com 1 flôr. $O$. alata Sem êsses caracteres $O$. violacea

Material examinado: RB. 125236, leg. W. Rodrigues e Coelho, 5893 em 8.6.1964; RB. 24409, leg. Ducke em 1.5.1932. 


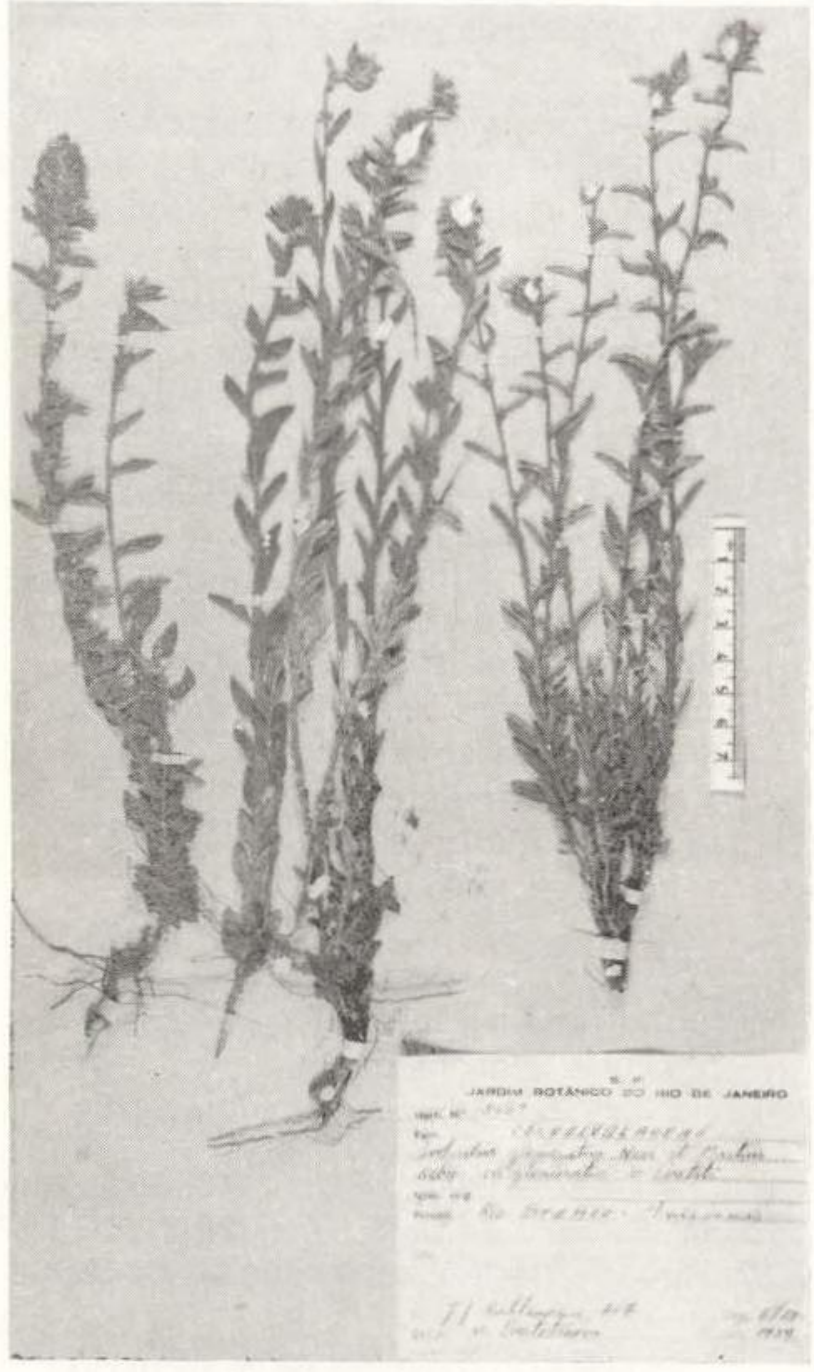

Fig. 3 - Evolvulus glomeratus Nees et Mart.

\section{S U M M A R Y}

In this paper a revision of Convolvulaceae of the State of Amazonas, Brazil, is made. 11 genera with the total of 40 spécies are studied.

Keys for the identification of each genus and each species are shown.

Results are documented by general characteristics of family, by short descriptions of each genus and by figures.

\section{BIBLIOGRAFIA CITADA}

DUCKE, A.

1922 - Plantes nouvelles ou peu connues de la région amazonienne II. Convolvulaceae. Arq. Jard. Bot., Rio de Janeiro, 3:248-250.

1925 - Plantes nouvelles ou peu connues de la région amazonienne III. Convolvulaceae. Arq. Jard. Bot., Rio de Janeiro, $4:$ 168-170.

1933 - Plantes nouvelles ou peu connues de la région amazonienne V. Convolvulaceae. Arq. Jard. Bot., Rio de Janeiro, $6: 83-87$.

FALCÃo, J. I. A.

1954 - Contribuição ao estudo das espécies brasileiras do gênero Merremia Dennst. Rodriguésia, Anos XVI e XVII, 28 e 29

MFISSNER, C. F.

1869 - Convolvulaceae in Martius, Flora Brasiliensis, $7: 198-390$, tab. $52-128$.

OOSTSTROom, S. J.

1934 - A monograph of the genus Evolvulus. Mede deelinger Bot. Mus. en Herb., Utrecht, $14: 1-127$. 